\title{
Establishment of Reference Range for Serum Creatinine by IDMS and NIST SRM 967 Traceable Calibrator in Government Kilpauk Medical College Hospital Laboratory
}

\author{
Dr. G. Komala ${ }^{1}$, Dr. K. Geetha ${ }^{2 *}$, Dr. Kishwanth ${ }^{3}$, Dr. M. Vijayalakshmi ${ }^{4}$, Dr. R. Nagendran ${ }^{5}$ \\ ${ }^{I}$ Dr.M.G.R. Medical University, Chennai, Senior Assistant Professor, (Presently Associate Professor, \\ Government Vellore Medical College, Vellore), Department of Biochemistry, Govt. Kilpauk Medical College, \\ Chennai-10 \\ ${ }^{2}$ Dr.M.G.R. Medical University, Chennai, Senior Assistant Professor, Department of Biochemistry, Govt. \\ Kilpauk Medical College, Chennai-10 \\ ${ }^{3}$ Post Graduate, Internal Medicine, Institute of Internal Medicine, RGGGH , Chennai \\ ${ }^{4}$ The Dr.M.G.R. Medical University, Chennai Senior Assistant Professor (Currently Associate Professor, \\ Governemnt Stanley Medical College, Chennai-1)Department of Biochemistry, Govt. Kilpauk Medical College, \\ Chennai-10 \\ ${ }^{5}$ Professor and HOD, Dr. M.G.R. Medical University, Department of Biochemistry, Govt. Kilpauk Medical \\ College, Chennai-10
}

*Corresponding Author: Dr. K. Geetha, Dr.M.G.R. Medical University, Chennai, Senior Assistant Professor, Department of Biochemistry, Govt. Kilpauk Medical College, Chennai-10

\begin{abstract}
An attempt to establish a reference range for serum creatinine using Uncompensated Jaffe's Kinetic method having calibrators traceable to IDMS, referenced to SRM 967 in Government Kilpauk Medical College Hospital Laboratory, Chennai, South India was made involving 254 healthy adult individuals. They were assessed for liver and renal functions. The reference range for creatinine was 1.15 $1.24 \mathrm{mg} / \mathrm{dl}$ for men and $0.96-1.04 \mathrm{mg} / \mathrm{dl}$ for women. The creatinine levels were not correlating with diet and age, but were correlated positively with mid arm circumference and gender. The derived reference range, deviated significantly from the global reference ranges, the range being very narrow and females having levels of creatinine higher than the globally reported range, could possibly be explained by the correlation of creatinine with ethnicity. The eGFR values calculated from the IDMS creatinine values, also showed narrow reference ranges in comparison to a similar study done in south Indian population at CARE Hospitals, Banjara Hills, Andhra Pradhesh. These newly established values of serum creatinine and eGFR may have their implications in the form of resetting standards for diagnosis of CKD in our population, if validated through multi-centric trials.
\end{abstract}

Keywords: Reference Range, calibrator, SRM 967, serum creatinine, creatinine clearance, eGFR

Abbreviations: IDMS- isotope dilution mass spectrometry, NIST- national institute of standards and technology, SRM- standard reference material, CKD- chronic kidney disease, NKDEP- National Kidney Disease Education Program, MDRD- modification of diet in renal disease, CKD-epi-chronic kidney diseaseepidemiology collaboration.

\section{INTRODUCTION}

Chronic Kidney Disease, the 12th leading cause of death and 17th leading cause of disability, according to WHO, is an independent risk factor for cardiovascular disease (CVD) [1]. Chronic kidney disease not only leads to other organ system complications but also progresses, if undiagnosed and uncorrected at the initial stages, to a condition called End Stage Renal Disease. Thus, it is necessary that Chronic Kidney Disease be diagnosed and treated at an earlier stage to prevent further complications.

Glomerular Filteration Rate, the rate at which the kidneys filter the plasma being an index of renal function, can be measured by renal clearance methods. But the whole concept of clearance is time 
consuming and cumbersome, and cannot be performed in every patient attending the Out Patient Unit. Therefore the concept of Estimated Creatinine Clearance $(\mathrm{eCrCl})$ and Estimated Glomerular Filteration Rate (eGFR) was put forth. The disadvantage of using MDRD equation is that only the Isotope Dilution Mass Spectrometry (IDMS) standardized creatinine values can be used. A new equation, CKD-EPI was introduced in 2009, but, is under study. In all these equations, serum creatinine value stays as the GFR determining variable. Hence, measurement of serum creatinine levels becomes necessary, to assess the kidney function.

The primary goal of laboratory medicine is to provide information that is useful to assist in medical decision-making thus allowing optimal health care [2]. Laboratories must also continuously assess their routine methods to ensure that they consistently produce accurate, medically useful and 'fit for purpose' results [3].

The first method for the measurement of serum creatinine levels was introduced by Max Jaffe in 1886, [4],but the method faces many analytical errors, due to the interference, provided by cephalosporins, dopamine, bilirubin and carbonyl compounds [6interferants], and the pseudochromogenic effect provided by the proteins present. Though the reference method for creatinine assay being IDMS, the Jaffe reaction using alkaline picrate remains the cornerstone of most current routine methods, attempting to overcome inherent analytical interferences and limitations. [5].

The serum creatinine concentrations obtained by the use of different measurement procedures have to be 'standardized' to the primary reference system, as suggested by NKDEP, in order to avoid obscuring results. The term "standardisation" encompasses the reference measurement procedures and reference materials required to achieve comparability of patient test values between different clinical assays [6]. This also ensures the traceability of results to an accepted reference measurement system with greater certainty that a result is close to the "true value $[3,7,8]$. This process ensures establishment of common reference interval for serum creatinine that can be used in all the laboratories worldwide.

The introduction of the global creatinine standard reference material SRM 967 [9] has had a major impact on the magnitude of serum and plasma creatinine values.SRM 967 is a frozen serum matrix which is used for calibration. Calibration is a process of testing and adjusting an instrument or a test system to establish a correlation between the measurement response and the concentration or amount of the substance that is being measured by the test procedure.

Standardized creatinine values have taken much importance due to its role in assessing the kidney function, indirectly using the estimated glomerular filteration rate. Earlier, the suggested formulae like the CockGraft Gault formula, Schwartz formula etc.for calculating eGFR used non-standardized creatinine values.

Foremost among the laboratory's problems is the poor comparability of analytical results that originate from different laboratories using different methods [ 6-8], and these differences restrict the use of a common reference interval for a particular analyte worldwide. Reference intervals for healthy subjects are very important for the clinical interpretation of laboratory test values [10], especially for the substances which are used as markers of certain diseases.

Serum creatinine, being a biological marker of renal function already has got a globally established reference range which is not applicable for every population as creatinine value is influenced by several factors like age, sex, muscle mass, diet pattern and ethnicity. With the establishment of a new reference range for serum creatinine, a reference range for eGFR can also be established for each population.

The Laboratory Working Group of the NKDEP suggests that the eGFR has to be reported using accurate and specific serum creatinine measurements, based on the concept of traceability because of its role in the assessment of renal function [3]. The MDRD and CKD-EPI [11], the two eGFR formulae, can be applied only with IDMS traceable creatinine values.

Thus this study was undertaken to establish a reference range for serum creatinine, using IDMS traceable calibrator, for the population served by Govt. Kilpauk Medical College Hospital Laboratory. 


\section{Materials AND Methods}

This cross - sectional study was conducted in the Department of Biochemistry of Govt. Kilpauk Medical College, Chennai-10.

For the above study, sample size was calculated using the formula:

Sample size $=\mathrm{Z} 1-\alpha / 22 \times \mathrm{SD} 2$

\section{$\mathrm{d} 2$}

$\mathrm{Z} 1-\alpha / 22=1.96$, is the standard normal variate at $\mathrm{p}<0.05$,

$\mathrm{d}$ is the absolute error or precision which is 0.5

$\mathrm{SD}$ is the standard deviation which is taken as $0.16 \mathrm{mg} / \mathrm{dl}$ for male and $0.15 \mathrm{mg} / \mathrm{dl}$ for female according to a study by Phillippa.K.Bailey et al. ${ }^{12}$

This gave a sample size of 39 for males in each age group and 36 samples for females in each age group. We decided to collect 40 samples for each of the 3 age groups, giving a total of 120 male samples and 120 female samples.

The number of subjects needed were 240. Healthy individuals aged between 18 to 60 years of age were selected of which were 120 males and 120 females. They were again subdivided into 3 groups with age as criterion, in each gender, as follows:

Sub-group 1(n=40) - 18 to 24 years of age.

Sub-group 2(n=40) -25 to 49 years of age.

Sub-group $3(\mathrm{n}=40)$ - 50to 60 years of age.

Inclusion Criteria was apparently healthy individuals aged between 18 to 60 years of age. Exclusion Criteria included patients with chronic disorders like Diabetes Mellitus, Hypertension, cancer, Cardiovascular diseases, renal disorders, patients under drug therapy (corticosteroid, cimetidine, trimethoprim), patients with muscular dystrophies and people with amputated limbs, pregnant women, malnourished individuals, individuals taking high meat or protein diet.

As healthy individuals above 50 years of age were difficult to find, all healthy individuals above 50 years were included in the study. Out of the 240 subjects, 6 male subjects were excluded because one male had an elevated bilirubin level, 2 had elevated GGT levels, 2 had elevated cholinesterase levels and 1 had elevated creatinine levels.

The Institutional Ethics Committee of Govt. Kilpauk Medical College, Chennai-10, approved the study. $5 \mathrm{ml}$ of fasting venous sample was drawn from the antecubital vein under aseptic conditions after obtaining informed consent from all the study participants.

Serum was separated by centrifugation at $3000 \mathrm{rpm}$ for 10 minutes, aliquoted into eppendorf and stored at $-20^{\circ} \mathrm{C}$ until further analysis. MERCK Microlab 300 was the instrument used for the semiautomated measurement of serum creatinine, by Uncompensated Jaffe's Kinetic methodology. The IDMS traceable calibrator, referenced to SRM 967 was obtained from Beckmann Coulter with lot no.0115 and control materials from BIORAD (2 levels-BIORAD medium and BIORAD high) and from MERCK - Labtrol (normal and pathological) were used. The reagents used were from TRANSASIA company and the following procedure was used to assay creatinine levels.

\section{Reagent Volume}

R1 Picric acid $-250 \mu 1$

R2 $\mathrm{NaOH}-250 \mu 1$

Reagents were freshly reconstituted before use and $10 \mathrm{~min}$ were allowed to lapse before the reagents were used for assay. The assay was done in fixed time mode in semiautomated instrument microlab300. Samples were assayed in batches with calibration from IDMS traceable Beckman Coulter calibrator and verified by running controls from BIORAD (2 levels-BIORAD medium and BIORAD high) and from MERCK - Labtrol (normal and pathological), for every batch. 
Establishment of Reference Range for Serum Creatinine by IDMS and NIST SRM 967 Traceable Calibrator in Government Kilpauk Medical College Hospital Laboratory

Liver and renal functions of the subjects were investigated by estimating serum glucose, urea, bilirubin (Total \& direct), AST, ALT, ALP, GGT, Albumin, LDH \& cholinesterase. These investigations helped in ruling out the exclusion criteria for the study, so that the subjects could be included. eGFR was calculated using MDRD and CKD-EPI formulae. Subjects demographic parameters like height, weight, BMI, midarm circumference, systolic and diastolic blood pressures were recorded.

Statistical analysis was performed using SPSS package version17. The groups were compared using analysis of Variance \& $\mathrm{t}$ test and $\mathrm{p}$ value of $<0.05$ was considered significant for $95 \%$ Confidence interval.

\section{RESULTS}

This study attempts to establish a reference range for the serum creatinine by Uncompensated Jaffe's Kinetic method with calibrator traceable to IDMS, referenced to SRM 967.

Quality Control Data: Based on biological variability, current desired goals for laboratory performance for creatinine measurements are $2.8 \%$ for inaccuracy and $2.2 \%$ for imprecision [13]. Considering both imprecision and inaccuracy, in making an estimate of analytical performance required to meet the clinical interpretation goals for serum creatinine measurements, the recommended desirable goal of $8.2 \%$ for total error [14] was achieved.

The study population was compared for height, BMI, midarm circumference, systolic and diastolic blood pressure, among the different age groups, and was found to be statistically significant as depicted in tables $1 \& 2$.

Table1. Comparison of BMI and Mid arm circumference

\begin{tabular}{|c|c|c|c|c|c|c|c|}
\hline Variable & Age group & $\mathrm{N}$ & Mean & Std. Dev & Min & Max & P-Value \\
\hline \multirow[t]{4}{*}{ Height in $\mathrm{cms}$} & $18-24$ & 82 & 166.39 & 9.480 & 142 & 185 & \multirow[t]{4}{*}{$<0.001$} \\
\hline & $25-49$ & 84 & 60.81 & 9.311 & 143 & 179 & \\
\hline & $50+$ & 88 & 157.94 & 10.701 & 104 & 179 & \\
\hline & Total & 254 & 161.62 & 10.435 & 104 & 185 & \\
\hline \multirow[t]{2}{*}{ Weight in kgs } & $18-24$ & 82 & 61.07 & 10.356 & 34 & 82 & \multirow[t]{2}{*}{0.171} \\
\hline & $25-49$ & 84 & 64.36 & 10.846 & 38 & 91 & \\
\hline \multirow[t]{4}{*}{ BMI kg/m2 } & $18-24$ & 82 & 21.99 & 2.914 & 15 & 33 & \multirow[t]{4}{*}{$<0.001$} \\
\hline & $25-49$ & 84 & 24.99 & 4.482 & 16 & 39 & \\
\hline & $50+$ & 88 & 25.26 & 6.748 & 16 & 74 & \\
\hline & Total & 254 & 24.11 & 5.210 & 15 & 74 & \\
\hline \multirow{4}{*}{$\begin{array}{l}\text { Midarm } \\
\text { circumference } \\
\text { in } \mathrm{cms}\end{array}$} & $18-24$ & 82 & 27.54 & 3.661 & 19 & 38 & \multirow[t]{4}{*}{0.013} \\
\hline & $25-49$ & 84 & 29.05 & 2.878 & 22 & 39 & \\
\hline & $50+$ & 88 & 28.34 & 3.231 & 21 & 39 & \\
\hline & Total & 254 & 28.31 & 3.313 & 19 & 39 & \\
\hline
\end{tabular}

Table2. Comparison of blood pressure

\begin{tabular}{|l|l|l|l|l|l|l|l|}
\hline Variable & Age group & $\mathrm{N}$ & Mean & Std. Dev & Min & Max & P-Value \\
\hline \multirow{3}{*}{$\begin{array}{l}\text { Systolic BP } \\
\text { mmHg }\end{array}$} & $18-24$ & 82 & 112.88 & 11.401 & 80 & 130 & $<0.001$ \\
\cline { 2 - 8 } & $25-49$ & 84 & 116.24 & 7.745 & 90 & 138 & \\
\cline { 2 - 7 } & $50+$ & 88 & 121.66 & 7.715 & 100 & 144 & \\
\cline { 2 - 7 } & Total & 254 & 117.03 & 9.747 & 80 & 144 & \\
\hline \multirow{3}{*}{$\begin{array}{l}\text { Diastolic } \\
\text { BP mmHg }\end{array}$} & $18-24$ & 82 & 77.78 & 8.062 & 60 & 92 & \multirow{2}{*}{0.021} \\
\cline { 2 - 7 } & $25-49$ & 84 & 79.69 & 6.471 & 70 & 90 & \\
\cline { 2 - 7 } & $50+$ & 88 & 80.68 & 5.824 & 70 & 90 & \\
\cline { 2 - 6 } & Total & 254 & 79.42 & 6.904 & 60 & 92 & \\
\hline
\end{tabular}

There was no difference between the levels of glucose and urea across the different age groups, as listed in table 3.

Table3. Comparison of blood glucose and urea values

\begin{tabular}{|l|l|l|l|l|l|l|l|}
\hline Variable & Age group & $\mathrm{N}$ & Mean & Std. Dev & Min & Max & P-Value \\
\hline $\begin{array}{l}\text { Glucose } \\
\text { mg/dl }\end{array}$ & $18-24$ & 82 & 72.71 & 13.504 & 24 & 100 & 0.186 \\
\cline { 2 - 8 } & $25-49$ & 84 & 76.66 & 15.235 & 25 & 112 & \\
\hline
\end{tabular}


Establishment of Reference Range for Serum Creatinine by IDMS and NIST SRM 967 Traceable Calibrator in Government Kilpauk Medical College Hospital Laboratory

\begin{tabular}{|c|c|c|c|c|c|c|c|}
\hline & $50+$ & 88 & 76.27 & 16.666 & 39 & 120 & \\
\hline & Total & 254 & 75.25 & 15.269 & 24 & 120 & \\
\hline \multirow[t]{4}{*}{ Urea $\mathrm{mg} / \mathrm{dl}$} & $18-24$ & 82 & 26.95 & 16.126 & 10 & 92 & \multirow[t]{4}{*}{0.089} \\
\hline & $25-49$ & 84 & 23.25 & 6.850 & 13 & 49 & \\
\hline & $50+$ & 88 & 25.16 & 6.937 & 12 & 46 & \\
\hline & Total & 254 & 25.11 & 10.837 & 10 & 92 & \\
\hline
\end{tabular}

Among the liver function tests, ALP, GGT and Direct Bilirubin (DB) showed significant difference across the different age groups but were well within normal limits, as depicted in tables $4 \& 5$.

Table4. Comparison of Liver function test values

\begin{tabular}{|c|c|c|c|c|c|c|c|}
\hline Variable & Age group & $\mathrm{N}$ & Mean & Std. Dev & Min & Max & P-Value \\
\hline \multirow[t]{4}{*}{ SGOT IU/1 } & $18-24$ & 82 & 21.56 & 12.494 & 7 & 91 & \multirow[t]{4}{*}{0.108} \\
\hline & $25-49$ & 84 & 24.98 & 12.786 & 9 & 73 & \\
\hline & $50+$ & 88 & 25.17 & 11.906 & 9 & 84 & \\
\hline & Total & 254 & 23.94 & 12.453 & 7 & 91 & \\
\hline \multirow[t]{4}{*}{ SGPT IU/l } & $18-24$ & 82 & 14.62 & 12.712 & 1 & 76 & \multirow[t]{5}{*}{0.345} \\
\hline & $25-49$ & 84 & 16.46 & 11.859 & 2 & 76 & \\
\hline & $50+$ & 88 & 16.91 & 6.854 & 2 & 41 & \\
\hline & Total & 254 & 16.02 & 10.724 & 1 & 76 & \\
\hline \multirow[t]{4}{*}{$\mathrm{DB} \mathrm{mg} / \mathrm{dl}$} & $18-24$ & 82 & 37 & 231 & 0 & 1 & \\
\hline & $25-49$ & 84 & 46 & 302 & 0 & 2 & \\
\hline & $50+$ & 88 & 61 & 372 & 0 & 2 & \\
\hline & Total & 254 & 48 & 323 & 0 & 2 & \\
\hline \multirow[t]{4}{*}{$\mathrm{TB} \mathrm{mg} / \mathrm{dl}$} & $18-24$ & 82 & 84 & 3.386 & 0 & 31 & \multirow[t]{4}{*}{0.380} \\
\hline & $25-49$ & 84 & 54 & 262 & 0 & 1 & \\
\hline & $50+$ & 88 & 1.54 & 7.524 & 0 & 71 & \\
\hline & Total & 254 & 98 & 4.831 & 0 & 71 & \\
\hline \multirow{4}{*}{$\begin{array}{l}\text { Cholinesterase } \\
\text { IU/1 }\end{array}$} & $18-24$ & 82 & 6152.6 & 2110.8 & 1236 & 11674 & \multirow[t]{4}{*}{0.101} \\
\hline & $25-49$ & 84 & 6507.9 & 2260.2 & 453 & 13326 & \\
\hline & $50+$ & 88 & 6885.2 & 2286.1 & 1207 & 13667 & \\
\hline & Total & 254 & 6523.9 & 2233.8 & 453 & 13667 & \\
\hline
\end{tabular}

Table5. Comparison of Liver function test values

\begin{tabular}{|c|c|c|c|c|c|c|c|}
\hline Variable & Age group & $\mathrm{N}$ & Mean & Std. Dev & Min & Max & P-Value \\
\hline & $18-24$ & 81 & 80.12 & 32.003 & 34 & 191 & \\
\hline & $25-49$ & 84 & 92.63 & 38.678 & 41 & 269 & \\
\hline \multirow[t]{7}{*}{ ALP IU/1 } & & & & & & & $<0.001$ \\
\hline & $50+$ & & 111.74 & 51.697 & 39 & 470 & \\
\hline & & 88 & & & & & \\
\hline & Total & 253 & 95.27 & 43.720 & 34 & 470 & \\
\hline & $18-24$ & & 277.93 & 70.849 & 27 & 393 & \\
\hline & & 82 & & & & & \\
\hline & $25-49$ & 84 & 317.61 & 246.935 & 16 & 2456 & \\
\hline \multirow[t]{6}{*}{ LDH IU/1 } & & & & & & & 0.205 \\
\hline & $50+$ & 88 & 285.75 & 63.844 & 101 & 394 & \\
\hline & Total & & & & & & \\
\hline & & 254 & 293.76 & 152.660 & 16 & 2456 & \\
\hline & $18-24$ & 82 & 4.47 & 0.562 & 3 & 6 & \\
\hline & $25-49$ & 84 & 4.58 & 0.579 & 3 & 7 & \\
\hline \multirow[t]{6}{*}{ Albumin $\mathrm{mg} / \mathrm{dl}$} & & & & & & & 0.441 \\
\hline & $50+$ & 88 & 4.51 & 0.545 & 4 & 6 & \\
\hline & Total & & 4.52 & 0.561 & 3 & 7 & \\
\hline & & 254 & & & & & \\
\hline & $18-24$ & 82 & 18.94 & 6.740 & 7 & 40 & \\
\hline & $25-49$ & 84 & 25.92 & 23.177 & 10 & 195 & \\
\hline \multirow[t]{3}{*}{ GGT IU/l } & & & & & & & 0.014 \\
\hline & $50+$ & 88 & 22.13 & 11.180 & 5 & 71 & \\
\hline & Total & 254 & 22.35 & 15.549 & 5 & 195 & \\
\hline
\end{tabular}


Establishment of Reference Range for Serum Creatinine by IDMS and NIST SRM 967 Traceable Calibrator in Government Kilpauk Medical College Hospital Laboratory

The 95th percentile reference interval for serum creatinine was determined among the reference population of healthy adults distributed as 254-

18- 24years - 40 males and 42 females

25-49 years - 39 males and 45 females

50 years and above -35 males and 53 females

The IDMS traceable creatinine values for the study population among the different age groups are as shown in table 6.

Table6. Reference range of creatinine for the different age groups and gender

\begin{tabular}{|l|l|l|l|l|l|l|}
\hline Gender & Variabels & Age group & $\mathrm{N}$ & Mean & Lower Bound & Upper Bound \\
\hline \multirow{4}{*}{ Male } & IDMS Creatinine & $18-24$ & 40 & 1.23 & 1.12 & 1.33 \\
\cline { 2 - 7 } & & $25-49$ & 39 & 1.19 & 1.14 & 1.25 \\
& & $50+$ & 35 & 1.17 & 1.10 & 1.24 \\
\cline { 2 - 7 } & & Total & 114 & 1.20 & 1.15 & 1.24 \\
\hline Female & IDMS Creatinine & $18-24$ & 42 & 0.95 & 0.90 & 1.00 \\
\hline & & $25-49$ & 45 & 1.03 & 0.96 & 1.10 \\
\hline & & $50+$ & 53 & 1.00 & 0.93 & 1.08 \\
\hline & & Total & 140 & 1.00 & 0.96 & 1.04 \\
\hline
\end{tabular}

These ranges significantly differ from the recommended common reference interval for global application of $0.6-0.9 \mathrm{mg} / \mathrm{dl}$ in females and $0.6-1.2 \mathrm{mg} / \mathrm{dl}$ in males.

When diet pattern was correlated to serum creatinine values, to find the influence of diet over serum creatinine, it was not found to be significant. (table :7).

The Estimated Glomerular Filteration Rate (eGFR) was calculated using IDMS standardized creatinine values with MDRD and CKD-EPI (table:8).

Table7. Correlation of IDMS creatinine with diet pattern

\begin{tabular}{|l|l|l|l|l|l|}
\hline Variables & & $\mathrm{N}$ & Mean mg/dl & Std. Deviation & P-Value \\
\hline IDMS creatinine & Veg & 28 & 1.11 & 0.243 & 0.980 \\
\hline & NV - Once amonth & 7 & 1.05 & 0.314 & \\
\hline & NV - Once a fortnight & 9 & 1.10 & 0.131 & \\
\hline & NV - Once a week & 120 & 1.10 & 0.290 & \\
\hline & NV - Twice a week & 54 & 1.06 & 0.271 & \\
\hline & NV - Alternate days & 24 & 1.09 & 0.159 & \\
\hline & NV - Daily & 12 & 1.08 & 0.177 & \\
\hline & Total & 254 & 1.09 & 0.261 & \\
\hline
\end{tabular}

Table8. Correlation of eGFR with age

\begin{tabular}{|c|c|c|c|c|c|c|}
\hline & & & & & $95 \% \mathrm{CI}$ for $\mathrm{m}$ & \\
\hline Gender & Variabels & Age group & $\mathrm{N}$ & Mean & Lower Bound & Upper Bound \\
\hline \multirow[t]{8}{*}{ Males } & \multirow[t]{4}{*}{ MDRD GFR in $\mathrm{ml} / \mathrm{min}$} & $18-24$ & 40 & 78.70 & 73.78 & 83.62 \\
\hline & & $25-49$ & 39 & 69.74 & 65.96 & 73.53 \\
\hline & & $50+$ & 35 & 66.74 & 61.68 & 71.81 \\
\hline & & Total & 114 & 71.96 & 69.22 & 74.71 \\
\hline & \multirow[t]{4}{*}{ CKD-EPI GFR ml/min } & $18-24$ & 40 & 88.28 & 82.92 & 93.63 \\
\hline & & $25-49$ & 39 & 78.10 & 73.83 & 82.37 \\
\hline & & $50+$ & 35 & 70.80 & 65.83 & 75.77 \\
\hline & & Total & 114 & 79.43 & 76.38 & 82.48 \\
\hline \multirow[t]{8}{*}{ Females } & \multirow{4}{*}{$\begin{array}{l}\text { MDRD GFR } \\
\mathrm{ml} / \mathrm{min}\end{array}$} & $18-24$ & 42 & 77.05 & 72.24 & 81.86 \\
\hline & & $25-49$ & 45 & 63.56 & 59.21 & 67.91 \\
\hline & & $50+$ & 53 & 61.81 & 57.53 & 66.09 \\
\hline & & Total & 140 & 66.94 & 64.19 & 69.69 \\
\hline & CKD-EPI GFR $\mathrm{ml} / \mathrm{min}$ & $18-24$ & 42 & 88.55 & 83.13 & 93.96 \\
\hline & & $25-49$ & 45 & 73.40 & 68.17 & 78.63 \\
\hline & & $50+$ & 53 & 68.21 & 63.43 & 72.98 \\
\hline & & Total & 140 & 75.98 & 72.76 & 79.19 \\
\hline
\end{tabular}




\section{DISCUSSION}

Laboratory medicine aims at providing information that are useful in medical decision making. These informations must be accurate, medically useful, fit-for-purpose which have to be ensured by all the laboratories. The lack of result comparability between different assays for a particular analyte, the differences in the pre-analytical conditions, the analytical method used and its traceability and the characteristics of the local population prevent use of common reference intervals for that analyte $[15,16]$. Reference intervals of certain analytes, for healthy subjects are very important for the clinical interpretation of laboratory test values [17].

The reference range of serum creatinine for our population when compared with the universally established standard reference range, was not only found to be very narrow across all age groups but also high, towards the higher end of the reportable range. The range of eGFR calculated based on these creatinine values, was found to be less than that of the global standards. This is in accordance with the study done by CARE Hospitals, Banjara Hills, Andhra Pradesh, where the assessment of serum creatinine was made using Enzymatic Method using calibrators traceable to IDMS SRM 967. The study reported range of serum creatinine between 0.97 and $0.99 \mathrm{mg} / \mathrm{dl}$ and the subjects having more than $1.1 \mathrm{mg} / \mathrm{dl}$ were evaluated for renal status and $97 \%$ of the people's GFR fell between 77.397 to $97.131 \mathrm{ml} / \mathrm{min} / \mathrm{BSA}$ having a mean value of $87.397 \mathrm{ml} / \mathrm{min} / \mathrm{BSA}$.

The range of serum cretinine obtained from our study was found to be $1.15-1.24 \mathrm{mg} / \mathrm{dl}$ in males and $0.96-1.04 \mathrm{mg} / \mathrm{dl}$ in females. The range of GFR calculated using these creatinine values was $69.22-$ $74.71 \mathrm{ml} / \mathrm{min} / \mathrm{BSA}$ in males and $64.69-69.69 \mathrm{in}$ females $\mathrm{ml} / \mathrm{min} / \mathrm{BSA}$ using MDRD equation; and was $76.38-82.48 \mathrm{ml} / \mathrm{min} / \mathrm{BSA}$ in males, $72.76-79.19 \mathrm{ml} / \mathrm{min} / \mathrm{BSA}$ using CKD-EPI equation.

Drawbacks in using the eGFR formulae in our set-up:

- The serum levels of creatinine measured in our set-up are not the true values, due to various measurement and pre-analytical errors during sample collection.

- The method used for estimating serum levels of creatinine is inappropriate.

- Serum creatinine measured using the normal assays should be calibrated, traceable to Isotope Dilution Mass Spectrometry [a reference method] which is not being done in our set up. Interpretation of eGFR needs to be done with IDMS calibration of creatinine.

- eGFR values can assess the state of kidney functions only if the serum creatinine values are reported accurately.

- A lack of normal reference range of creatinine in this population. The normal level of serum creatinine differs among various populations. There is no properly established reference value for creatinine in south Indian population.

- Use of any serum creatinine based estimate requires that kidney function be at a steady state, so any estimate must be used cautiously in hospitalized patients with rapidly changing kidney function.

- The MDRD and CKD-EPI equations are used to calculate eGFR/1.73 m2 of body surface area which is applicable only for the western population. So the eGFR formulae need to be adjusted for average body surface area of our population.

- So the whole concept of eGFR can be brought into practice in this clinical setup, only by creatinine calibration to a reference method (IDMS), by setting a cut-off value (reference range) of the same, and adjusting the formulae for body surface area of our population.

- According to a study done by Sajja et al, CARE Hospital, Banjara Hills, Hyderabad, Andhra Pradesh, the creatinine levels in the study population was found to be between $0.97-0.99 \mathrm{mg} / \mathrm{dl}$ in both males and females; those having values greater than $1.1 \mathrm{mg} / \mathrm{dl}$ were subjected to renal status evaluation and the range of eGFR calculated based on the IDMS creatinine was from 77.397 to $97.131 \mathrm{ml} / \mathrm{min} / \mathrm{BSA}$. As, creatinine value is also altered by race, Indian population would have a range of serum creatinine concentration differing from the western population. 
- Since, it's practically impossible for every laboratory, to use IDMS, calibrators are used that are traceable to IDMS SRM-967, whichever be the instrument in use in that particular laboratory.

- Impact of IDMS standardized Creatinine Values ${ }^{18}[18]$

- Standardization of creatinine assays will lead to less variation in estimating kidney function and more consistent drug dosing.

- The relationship between creatinine results before and after standardization will be different for each specific method and instrument used in clinical laboratories.

- Using standardized creatinine values, the accuracy of estimated kidney function will depend upon whether or not an equation was developed using IDMS traceable creatinine values.

It is not possible to have a single, uniform conversion formula or factor to relate IDMS.

Large clinical trials with adequate sample size and multi-centric trials can help in assessing the reference range for Indian population. The values of serum creatinine, in our study, were obtained using Uncompensated Jaffe's Kinetic method which is the widely used method across all the laboratories in India. A better establishment of reference range, close to the true values could have been obtained if the Enzymatic method was used.

In order to get an ideal and true estimate of GFR using the measured serum creatinine values, the best possible method would be to measure the GFR using renal clearance methods and at the same time using eGFR equations with IDMS creatinine values. The narrow reference range of serum creatinine and eGFR for our population, in the absence of any confounding variable could be attributed to the ethnicity of our population, which also influences serum creatinine concentration.

\section{LIMITATIONS OF THE STUDY}

The narrow range of serum creatinine obtained needs further investigation with a large sample size. Multi -centric studies have to be conducted in order to establish a common reference range for serum creatinine for the entire population, which would in turn help in establishing a new range for GFR. The newly established reference range might lead to amendments or redefinition of CKD for our population.

Establishing a reference range for eGFR also helps in proper drug dosing adjustments in patients, and in turn avoiding unnecessary investigations in subjects suspected to have renal insufficiency, thereby saving time, money and enhancing the quality of life just by reassurance.

Interference contributed by antibiotics like cephalosporin during creatinine assay must be recognised and the subjects must be enquired for the history of antibiotic intake in future studies.

The increased amount of interference encountered in creatinine assay by Jaffe based methods mandates more specific methods like Enzymatic method to get true values of serum creatinine.

\section{SUMMARY OF OUR OBSVERATIONS}

Study on serum creatinine reference intervals in adults using Jaffe's Kinetic traceable to the IDMS SRM 967:

\begin{tabular}{|l|l|}
\hline Year & 2012 \\
\hline Method & Jaffe's Kinetic Method \\
\hline Analytical system & MICROLAB 300 \\
\hline Subjects & \\
\hline$*$ Race & Dravidians \\
\hline *Source & Volunteers \\
\hline$*$ Number and sex & 254,114 males, 140 females \\
\hline Age, years & $18-24,25-49,50$ and above \\
\hline Sample & Fasting venous blood sample \\
\hline Study population & Reference intervals \\
\hline & Creatinine $\mathrm{mg} / \mathrm{dl}$ \\
\hline$*$ Males (age in years) & \\
\hline $18-24$ & $1.12-1.33$ \\
\hline
\end{tabular}


Establishment of Reference Range for Serum Creatinine by IDMS and NIST SRM 967 Traceable Calibrator in Government Kilpauk Medical College Hospital Laboratory

\begin{tabular}{|l|l|}
\hline $25-49$ & $1.14-1.25$ \\
\hline 50 and above & $1.10-1.24$ \\
\hline Total & $1.15-1.24$ \\
\hline Females (age in years) & \\
\hline $18-24$ & $0.90-1.00$ \\
\hline $25-49$ & $0.96-1.10$ \\
\hline 50 and above & $0.93-1.08$ \\
\hline Total & $0.96-1.04$ \\
\hline & GFRbyusingMDRDequation \\
\hline$*$ Males & (ml/min/BSA) \\
\hline $18-24$ & \\
\hline $25-49$ & $73.78-83.62$ \\
\hline 50 and above & $65.96-73.53$ \\
\hline
\end{tabular}

\section{CONCLuSion}

The study done to establish a reference range of serum creatinine, measured using a calibrator traceable to IDMS SRM-967, for our population, revealed a range which deviated significantly from the global reference ranges, not only narrow but also the levels were high and towards the higher end of the global standards. From the derived range it was found that females had levels of creatinine higher than the globally reported range which could possibly be explained by the correlation of creatinine with ethnicity. The reference range of eGFR, as calculated using MDRD and CKD-EPI equations, was found to be low and also narrow for our population as it has got an inverse relation with serum creatinine concentrations.

\section{ACKNOWLEDGEMENT}

We gratefully acknowledge Indian Council of Medical Research for their part funding of Rs.10000 under the STS-2012 scheme for this research work. Grant Number 2012-00220 granted to Kishwant, II MBBS student.

\section{ETHICAL APPROVAL}

All procedures performed in studies involving human participants were in accordance with the ethical standards of the institutional and/or national research committee and with the 1964 Helsinki declaration and its later amendments or comparable ethical standards."

\section{INFORMED CONSENT}

Informed consent was obtained from all individual participants included in the study.

\section{REFERENCES}

[1] Taussky H. A procedure increasing the specificity of the Jaff\#\{233\} reaction method. Clin Chim Acta 1956;1:210-24.

[2] Panteghini M. Traceability, Reference Systems and Result Comparability. Clin Biochem Rev; August 2007; 28(3): 97.

[3] Tate J, Panteghini M. Standardisation - The Theory and the Practice. Clin Biochem Rev; August 2007; 28(3): 93-94.

[4] Joris R. Delanghe and Marijn M. Speeckaert: Creatinine determination according to Jaffe - what does it stand for?. NDT Plus Advance Access published January 27, 2011, 0: 1-4.

[5] Levey AS, Stevens LA, Schmid CH, Zhang YL, Castro AF, Feldman HI, et al., for the CKD-EPI (Chronic Kidney Disease Epidemiology Collaboration). A new equation to estimate glomerular filtration rate. Ann Intern Med. 2009;150: 604 - 12.

[6] Thienpont LM, Stöckl D, Kratochvila J, Friedecky B, Budina M. Pilot external quality assessment survey for post-market vigilance of in vitro diagnostic medical devices and investigation of trueness of participants results. Clin Chem Lab Med 2003;41:183-6.

[7] Miller WG, Myers GL, Ashwood ER, Kileen AA, Wang E, Thienpont LM, et al. Creatinine measurement: state of the art in accuracy and interlaboratory harmonization. Arch Pathol Lab Med 2005;129:297-304 
[8] Jansen R, Schumann G, Baadenhuijsen H, Franck P, Franzini C, Kruse R, et al. Trueness verification and traceability assessment of results from commercial systems for measurement of six enzyme activities in serum: an international study in the EC4 framework of the Calibration 2000 project. Clin Chem Acta 2006;368:160-7.

[9] Panteghini M. Enzymatic assays for creatinine: time for action. Scand J Clin Lab Invest 2008; 241 (Suppl): 84-88.

[10] Flegar-Mes 'tric' et al. Applicability of common reference intervals for serum creatinine concentrations to the Croatian population. Clin Chem Lab Med 2010; 48(2):231-235.

[11] Delanaye P, Cavalier E, Mariat C, Mailard N, Krzesinski J. MDRD or CKD-EPI study equations for estimating prevalence of stage $3 \mathrm{CKD}$ in epidemiological studies: which difference? Is this difference relevant? BMC Nephrology; 2010, 11:8 http://www.biomedcentral.com/1471-2369/11/8.

[12] Bailey PK, Tomson CR, Kinra S, Ebrahim S, Radhakrishna KV, Kuper H, Nitsch D, Ben-Schlomo Y: Differences in estimation of creatinine generation between renal function estimating equations in an Indian population: cross-sectional data from the Hyderabad arm of the Indian migration study. BMC Nephrol 2013, 14:30.

[13] Ricos C, Alvarez V, Cava F, Garcia-Lario JV, Hernandez A, Jimenez CV, et al. Current databases on biological variation: pros, cons and progress. Scand J Clin Lab Invest 1999; 59:491-500. The 2008 update. http://www.westgard.com/guest26.htm.

[14] Myers GL, Miller WG, Coresh J, Fleming J, Greenberg N, Greene T, et al. Recommendations for improving serum creatinine measurement: a report from the Laboratory Working.

[15] Haecke R. Assay of creatinine in serum, with use of Fuller's earth to remove interferents. Cliii Chem $1981 ; 27: 179-83$.

[16] Gorter E, de GraafWC. Determination of creatinine in serum without deproteunization. In: Lubsen $\mathrm{N}$, Becker JH, de Vries LA, eds. Klinische Diagnostiek, 7th ed. Leiden, The Netherlands: HE Stenfort Kroese N.y., 1955:278-81.

[17] Chasson AK, Grady HJ, Stanley MA. Determination of creatmine by means of automatic analysis. Am J Clin Pathol 1961; 35:83-8.

[18] National Kidney Disease Education Program (NKDEP). Suggestions for laboratories (December 2005). http://www.nkdep.nih.gov/resources/laboratories_reporting.htm. Accessed 1 June 2006.

Citation: G. Komala et al., "Establishment of Reference Range for Serum Creatinine by IDMS and NIST SRM 967 Traceable Calibrator in Government Kilpauk Medical College Hospital Laboratory", International Journal of Clinical Chemistry and Laboratory Medicine (IJCCLM), vol. 3, no. 3, pp. 23-32, 2017. http://dx.doi. org/10.20431/2455-7153.0303005

Copyright: (C) 2017 Authors. This is an open-access article distributed under the terms of the Creative Commons Attribution License, which permits unrestricted use, distribution, and reproduction in any medium, provided the original author and source are credited. 